\title{
Sociodemographic Representativeness in a Nationwide Web-Based Survey of the View of Men on Involvement in Health Care Decision-Making: Cross-Sectional Questionnaire Study
}

Søren F Birkeland ${ }^{1}$, LLM, MD, PhD; Anders K Haakonsson ${ }^{1}, \mathrm{MSc}, \mathrm{PhD}$; Susanne S Pedersen ${ }^{2,3}$, MSc, PhD; Nina Rottmann ${ }^{2,4}$, MSc, PhD; Michael J Barry ${ }^{5}$, MD; Sören Möller ${ }^{1}$, MSc, PhD

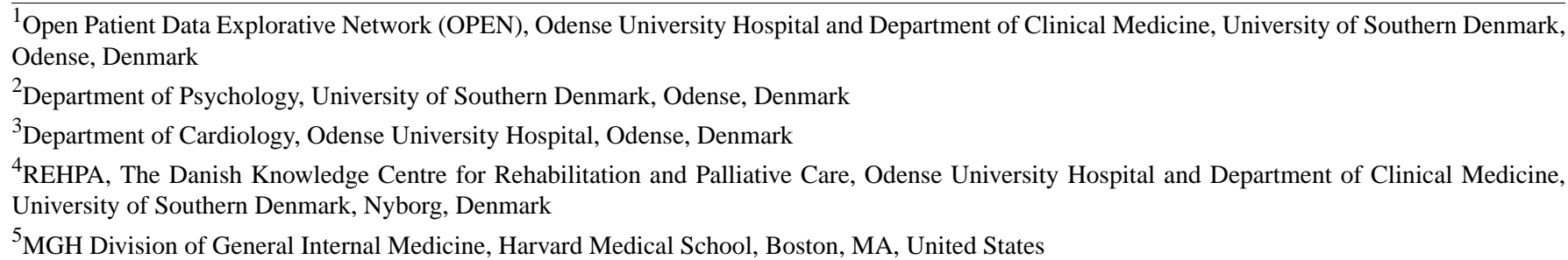

Corresponding Author:

Søren F Birkeland, LLM, MD, PhD

Open Patient Data Explorative Network (OPEN)

Odense University Hospital and Department of Clinical Medicine

University of Southern Denmark

J. B. Winsløws Vej 9 a, 3. floor

Odense, DK-5000

Denmark

Phone: 4529166730

Email: sbirkeland@health.sdu.dk

\section{Abstract}

Background: Being able to generalize research findings to a broader population outside of the study sample is an important goal in surveys on the internet. We conducted a nationwide, cross-sectional, web-based survey with vignettes illustrating different levels of patient involvement to investigate men's preferences regarding participation in health care decision-making. Following randomization into vignette variants, we distributed the survey among men aged 45 to 70 years through the state-authorized digital mailbox provided by the Danish authorities for secure communication with citizens.

Objective: This study aimed to investigate the sociodemographic representativeness of our sample of men obtained in a nationwide web-based survey using the digital mailbox.

Methods: Response rate estimates were established, and comparisons were made between responders and nonresponders in terms of age profiles (eg, average age) and municipality-level information on sociodemographic characteristics.

Results: Among 22,288 men invited during two waves, a total of 6756 (30.31\%) participants responded to the survey. In adjusted analyses, responders' characteristics mostly resembled those of nonresponders. Response rates, however, were significantly higher in older men (odds ratio [OR] 2.83 for responses among those aged 65-70 years compared with those aged $45-49$ years, $95 \% \mathrm{CI}$ $2.58-3.11 ; P<.001)$ and in rural areas (OR 1.10 compared with urban areas, 95\% CI 1.03-1.18; $P=.005$ ). Furthermore, response rates appeared lower in areas with a higher tax base (OR 0.89 in the highest tertile, 95\% CI 0.81-0.98; $P=.02$ ).

Conclusions: Overall, the general population of men aged 45 to 70 years was represented very well by the responders to our web-based survey. However, the imbalances identified highlight the importance of supplementing survey findings with studies of the representativeness of other characteristics of the sample like trait and preference features, so that proper statistical corrections can be made in upcoming analyses of survey responses whenever needed.

(J Med Internet Res 2020;22(9):e19517) doi: 10.2196/19517 


\section{KEYWORDS}

research methodology; electronic data capture; internet-based survey; representativeness; generalizability; user involvement; patient satisfaction; bioethics; medical law; cancer

\section{Introduction}

Research has suggested that communication breaches are underlying issues in many complaints about health care delivery [1-3]. Beckman et al found that patients' feelings of being deserted and poor information delivery were central themes in malpractice suits, and later research pointed in the same direction [2,3]. Insufficient patient involvement in decision-making has therefore been proposed as an important underlying issue when people file a malpractice complaint [4-6]. People's lack of "ownership" of decisions about the care they have received may very well be an underlying cause in many complaints, and perhaps this is particularly the case if treatment leads to an undesirable outcome. Nonetheless, even if greater patient involvement seems to be an obvious starting point to increase patient satisfaction with health care and prevent complaints, there is still scant research to support this notion.

We therefore conducted a cross-sectional questionnaire study to increase our understanding of patient preferences for involvement in health care decision-making. The study was designed as a nationwide internet survey in the general population benefiting from the opportunities in Denmark for survey distribution through a web portal used for communication between authorities and citizens. As is the case with other survey approaches, however, using the internet for data collection may raise concerns about nonresponse bias and sample representativeness [7]. A representative survey sample can be defined as "one that has strong external validity in relationship to the target population the sample is meant to represent" [8] This implies that results from the survey analyses can be generalized with confidence to the population of interest. Correspondingly, nonresponse and poor coverage of the sample may bias survey findings if the responding sample differs from the characteristics of the target population in nonnegligible ways [8]. For example, responders may more often be better off economically than the target population, thereby lowering the sample's representativeness [8]. Similarly, response rates (RRs) may vary with age and location (eg, areas with various ethnic populations) [9]. In this paper, we report on the representativeness of our web-based survey in terms of sociodemographic characteristics through comparisons of our sample with nonresponders and national statistics data.

\section{Methods}

\section{Setting and Participants}

We used a web platform (REDCap [10]) for the survey and identified the sample with civil registration numbers through use of the Danish Health Data Authority (DHDA). Danish citizens are all registered in the civil registration system with unique personal identification numbers. We recruited participants using personal invitations delivered to the participants through coupling of civil registration numbers to the "digital mailbox" provided by the Danish authorities for safe communication with citizens. Adult Danish citizens are registered to use the digital mailbox as default, although a small proportion of citizens have actively deregistered (9.9\% in 2017) [9]. Digital mailbox communication is encrypted, and thus, its security is higher than that of usual email and mails sent by regular postal service [9].

\section{Variables and Measurement}

The survey illustrated various levels of patient involvement in health care decision-making through use of multiple case vignette versions. We used decision-making with regard to having a prostate-specific antigen (PSA) test for prostate cancer (PCa) screening as a model situation and measured responders' imagined satisfaction with health care and readiness to initiate malpractice litigation about the health care received. Responders were randomized into one of 30 different scenarios with an identical core structure. There were differences regarding the degree of patient involvement (five levels), the decision to have a PSA test, and outcomes (three possibilities; details have been provided previously [11]). Measures comprised standardized validated instruments (eg, personality) and purpose-designed questions (eg, sociodemographic characteristics). Regarding participant age, we chose the age range of 45 to 70 years with reference to international guidelines about $\mathrm{PCa}$ screening $[12,13]$. During survey development, we collaborated with male adult health user representatives to optimize the survey's content and acceptability.

We examined the overall representativeness of the sample obtained through the procedures described above. We estimated RRs and compared responders and nonresponders with respect to their age profile. Furthermore, we made comparisons regarding municipality-level sociodemographic characteristics derived from the 98 municipality codes available from the Danish municipality statistics database [14]. Data were used as standard measures for the state and municipalities in Denmark, as well as for research purposes, and included statistics information of municipality-level population density, tax per citizen figures, proportion of citizens with higher education, and proportion of citizens of non-Western origin [15,16]. Reporting in this article follows the STROBE (Strengthening the Reporting of Observational Studies in Epidemiology) guidelines for observational studies [17].

\section{Study Size, Quantitative Variables, and Statistical Methods}

For the project, we drew a random sample of 12,000 male Danish health care users in the age range of 45 to 70 years, according to the following sample size estimation. When the primary outcome measure (readiness to complain) was targeted, 100 participants per subgroup were needed to obtain a 0.90 power to detect a 0.45 SD ("medium") effect between groups with a $5 \%$ risk of type 1 error and a bidirectional two-sample homoscedastic $t$ test $[18,19]$. To compensate for nonresponse and subgroup skewness, we intended to include an additional 300 participants per group, thereby totaling 12,000 participant 
invitations (400 per group and 30 groups) [20]. In order to anticipate the possibility of even lower participation, we obtained DHDA permission for sending up to 36,000 invitations in total (through up to three consecutive waves). Ultimately, two waves of surveys were required to achieve the necessary sample size.

We present RRs as counts and proportions, with stratification into 5-year age groups, survey wave groups (the person was part of which of the two survey waves), and municipality types (four categories) [21]. We compared the proportions between the groups by logistic regression (both unadjusted and mutually adjusted) and compared the participants with the general population by logistic regression with weights according to population size, using data from Statistics Denmark [22]. Comprehensive digital mailbox systems like the Danish system are not in place in all countries. Therefore, to get an impression of the general representativeness of our sample, we compared responders to all nonresponders in "A comparisons" without consideration for their opportunity to respond (having the digital mailbox). In "B comparisons," we made comparisons between responders and nonresponders among those having the digital mailbox only in order to accentuate any active decision on whether to participate. Conducting both comparisons in parallel is necessary to allow for taking into account digital mailbox noncoverage and to rule out that we only obtained responses from a highly selected group of the population through our web-survey solution. Odds ratios (ORs) denote the probability of response (ie, OR >1 means more likely to respond). Analyses were carried out using Stata version 15.0 (Stata Corp LP).

\section{Ethics Approval and Consent to Participate}

When conducting web-based surveys, ethical issues may arise with regard to procuring valid informed consent and respecting responders' privacy [7]. The Regional Scientific Ethics Committee for Southern Denmark evaluated the project and concluded that the project could be implemented without their permission (case number 20182000-99). However, after ensuring that data management was in compliance with EU regulation 2016/679 and Directive 95/46/EC, General Data Protection Regulation, we obtained Data Protection Agency authorization through the regional municipality and DHDA permission to conduct the survey (number FSEID-00003692). Invitation letters to potential participants explained the purpose of the study and were distributed with a link to the questionnaire. Considering a person's privilege to decline participation in our study, in addition to the introductory invitation letter, we considered that it was appropriate to send only one reminder after 14 days to augment the RR.

\section{Results}

Participants were invited on January 24, 2019, and one reminder was sent after 14 days. To obtain a satisfactory sample size $(n=100)$ in all $(n=30)$ questionnaire variants, two consecutive waves of invitations were necessary. The second wave of invitations was sent out on March 07, 2019, with a reminder after 14 days. We thereby obtained a sample of 6756 participants. The flow chart is presented in Figure 1, and sample characteristics are presented in Table 1.

Figure 1. Flowchart showing the inclusion of study participants.

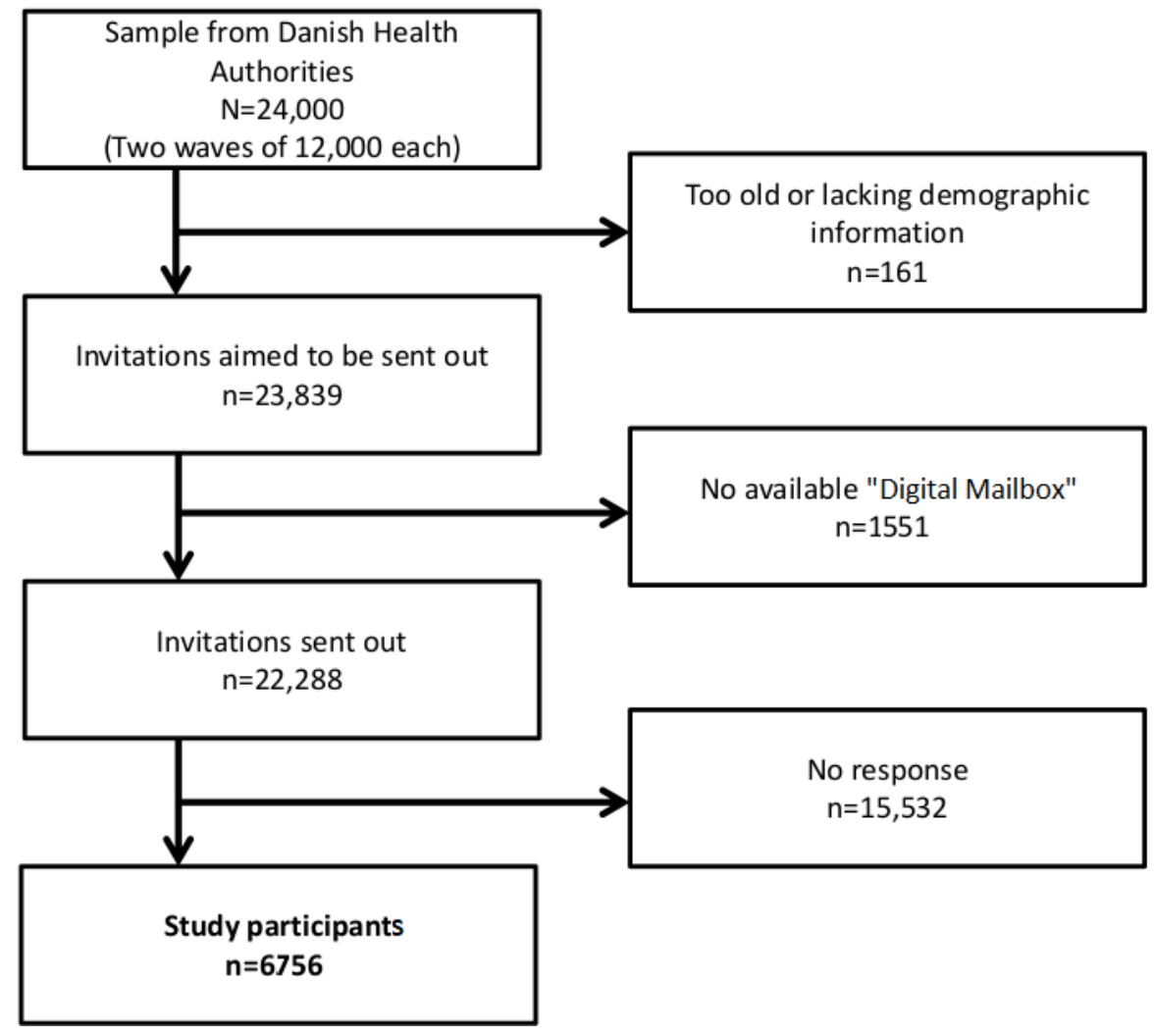

Among 161 excluded individuals, 117 were excluded because they either were too old or had unknown age according to register information from DHDA, 6 were excluded as they explicitly asked to be deleted from the research project, and 38 
were excluded because they were too old when they responded to the survey. The overall RR was $30.31 \%(6756 / 22,288)$ among digital mailbox invitations and $28.34 \%(6756 / 23,839)$ in the general population. It appears from our study that the digital mailbox covered $93.49 \%(22,288 / 23,839)$ of our target population.

Table 1. Sample characteristics.

\begin{tabular}{|c|c|c|c|}
\hline Characteristic & $\begin{array}{l}\text { Responders }{ }^{\mathrm{a}}(\mathrm{N}=6756), \text { median } \\
(\mathrm{IQR}) \text { or } \mathrm{n}\end{array}$ & $\begin{array}{l}\text { Nonresponders }(\mathrm{N}=15,532) \text {, me- } \\
\text { dian (IQR) or } \mathrm{n}\end{array}$ & $\begin{array}{l}\text { No digital mailbox }(\mathrm{N}=1551) \text {, } \\
\text { median (IQR) or } \mathrm{n}\end{array}$ \\
\hline Age (years) & $59(53-65)$ & $55(50-62)$ & $60(54-66)$ \\
\hline $45-49(\mathrm{~N}=4721)$ & 935 & 3633 & 153 \\
\hline $50-54(\mathrm{~N}=5256)$ & 1225 & 3751 & 280 \\
\hline $55-59(\mathrm{~N}=4804)$ & 1368 & 3147 & 289 \\
\hline $60-64(\mathrm{~N}=4276)$ & 1406 & 2515 & 355 \\
\hline $65-70(\mathrm{~N}=4782)$ & 1822 & 2486 & 474 \\
\hline \multicolumn{4}{|l|}{ Municipality type } \\
\hline Urban municipality $(\mathrm{N}=10,564)$ & 2828 & 7049 & 687 \\
\hline Rural municipality (N=6962) & 2042 & 4443 & 477 \\
\hline Urban-rural municipality $(\mathrm{N}=3947)$ & 1183 & 2525 & 239 \\
\hline Outskirts municipality (N=2366) & 703 & 1515 & 148 \\
\hline \multicolumn{4}{|l|}{ Invitation wave } \\
\hline Wave $1(\mathrm{~N}=11,869)$ & 3395 & 7716 & 758 \\
\hline Wave $2(\mathrm{~N}=11,970)$ & 3361 & 7816 & 793 \\
\hline
\end{tabular}

${ }^{\mathrm{a}}$ Responder numbers and response rates regarding the 30 different questionnaire variants of the survey are shown in Multimedia Appendix 1.

In Tables 2 and 3, responders and nonresponders are compared.

It appeared that older men and men from rural areas had higher

RRs. 
Table 2. Comparison of responders and nonresponders according to age and dwelling.

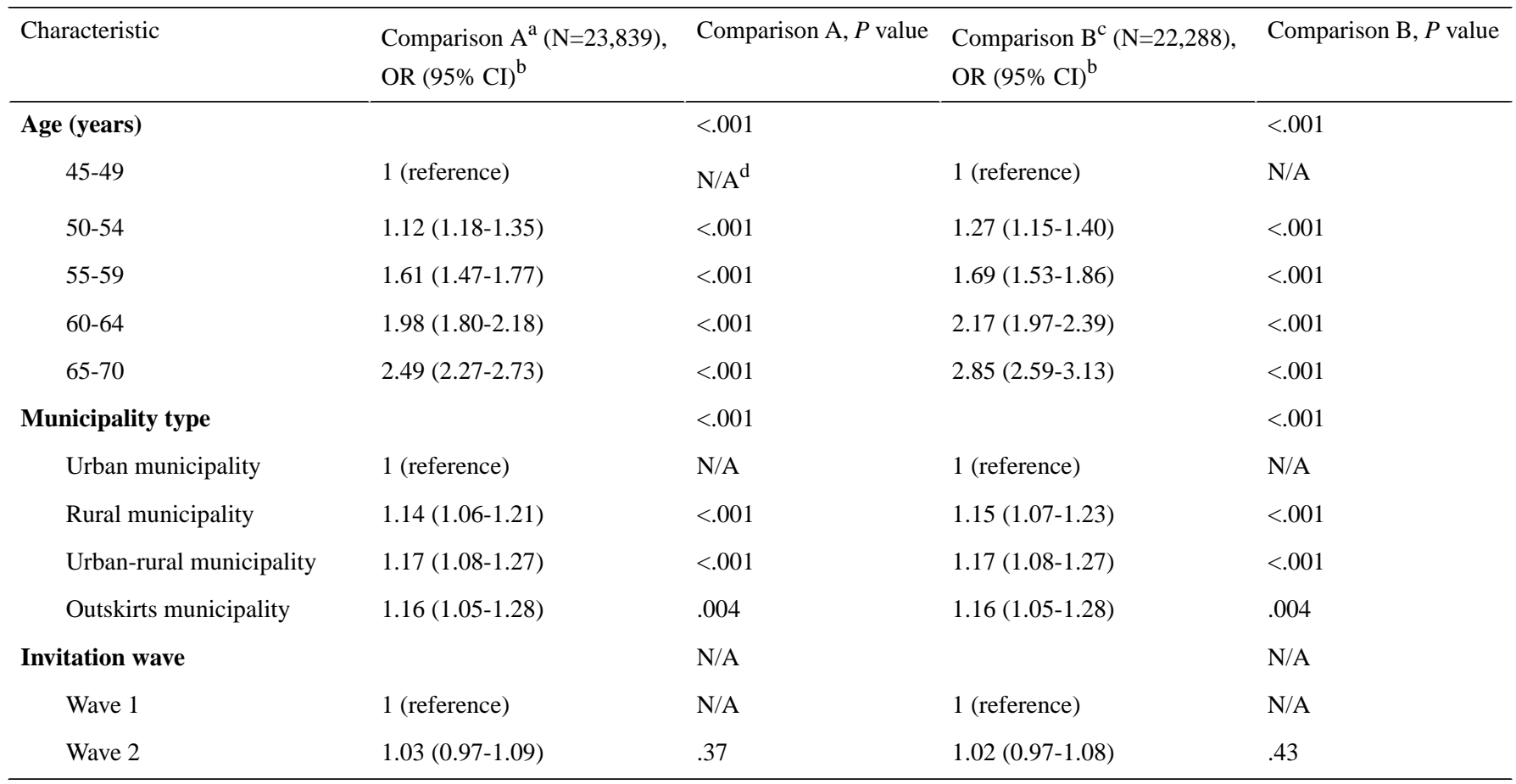

${ }^{\mathrm{a} C}$ Comparison A compares responders to all nonresponders with or without the digital mailbox.

${ }^{\mathrm{b}}$ Odds ratios (ORs) denote the probability of response (ie, OR >1 means more likely to respond).

${ }^{\mathrm{c}}$ Comparison $\mathrm{B}$ compares responders to nonresponders with the digital mailbox.

${ }^{\mathrm{d}} \mathrm{N} / \mathrm{A}$ : not applicable.

Table 3. Comparison of responders and nonresponders according to age and dwelling adjusted for age, municipality, and wave.

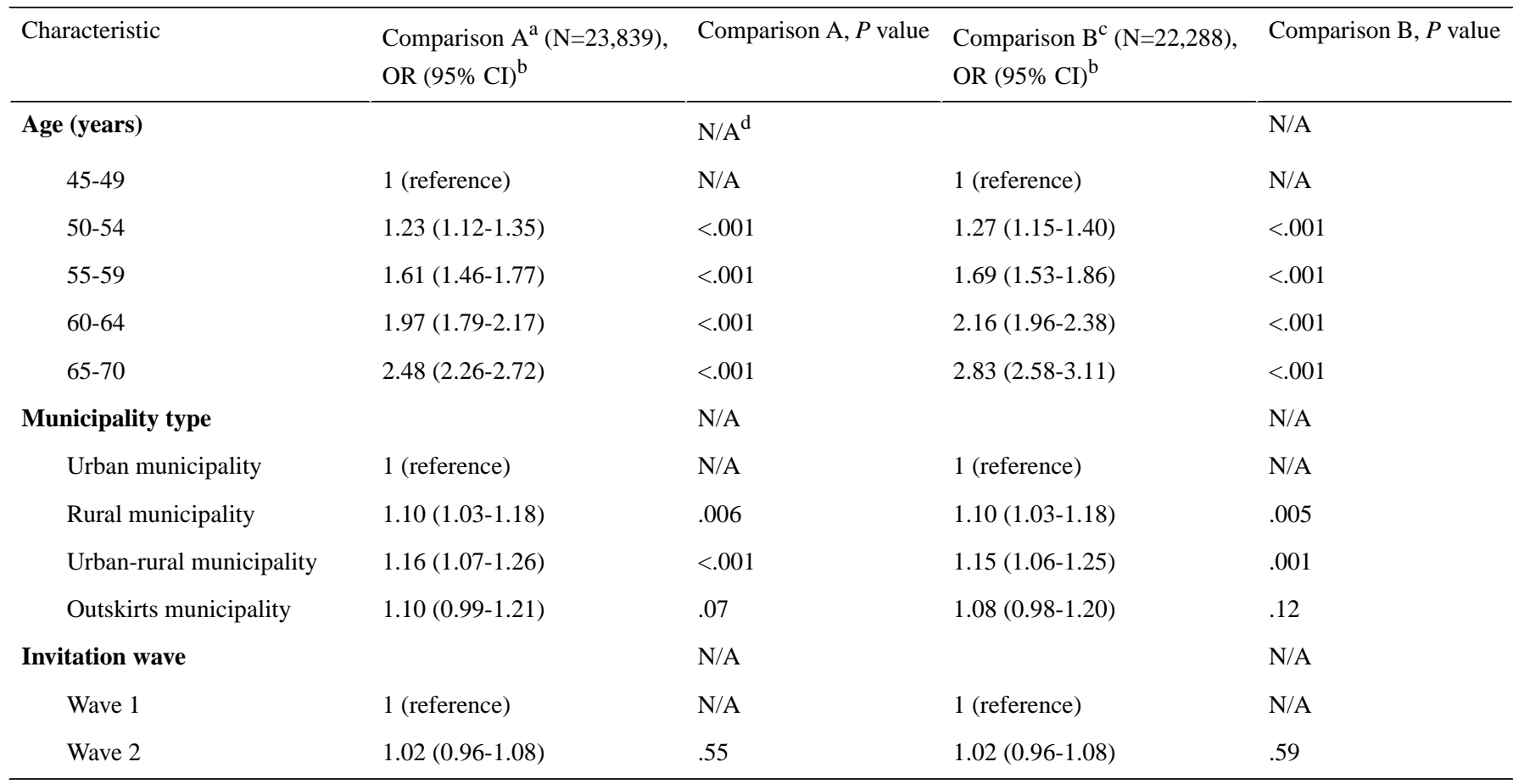

${ }^{\mathrm{a} C}$ Comparison A compares responders to all nonresponders with or without the digital mailbox.

${ }^{\mathrm{b}}$ Odds ratios (ORs) denote the probability of response (ie, OR >1 means more likely to respond).

${ }^{\mathrm{c}}$ Comparison $\mathrm{B}$ compares responders to nonresponders with the digital mailbox.

$\mathrm{d}_{\mathrm{N}} / \mathrm{A}$ : not applicable. 
Table 4 illustrates the statistical differences between responders and nonresponders across questionnaire variants. One would expect a tendency toward lower RRs with increasing length of the questionnaire, that is, with higher group number from 1 through 10 and from main variant A through C. However, no clear association could be demonstrated.

As a proxy for the amount of resources required to complete the survey, we measured the time used by responders across variants (Multimedia Appendix 2). It is worth noting that no relevant difference could be established regarding response time across questionnaire variants. Correspondingly, when looking at RRs, no clear relevant association appeared between questionnaire variant and RR. Although "Group 10" had a notably lower RR than did the other groups, "Group 9" that had a similar length demonstrated no decrease in the RR.

Table 5 compares responders with the entire Danish population of men aged 45 to 70 years. It appears that compared with the general population, younger men and urban men are underrepresented in the sample.

Table 4. Comparison of responders and nonresponders regarding questionnaire variants.

\begin{tabular}{|c|c|c|c|c|}
\hline Variants & $\begin{array}{l}\text { Comparison } \mathrm{B}^{\mathrm{a}}(\mathrm{N}=22,288) \text {, } \\
\text { OR }(95 \% \mathrm{CI})^{\mathrm{b}}\end{array}$ & Comparison $\mathrm{B}, P$ value & $\begin{array}{l}\text { Adjusted comparison } \mathrm{B}^{\mathrm{a}} \\
(\mathrm{N}=22,288), \mathrm{OR}(95 \% \mathrm{CI})^{\mathrm{b}, \mathrm{c}}\end{array}$ & $\begin{array}{l}\text { Adjusted comparison } \mathrm{B}, \\
P \text { value }\end{array}$ \\
\hline $\begin{array}{l}\text { Randomization and vignette } \\
\text { type }\end{array}$ & \multicolumn{3}{|c|}{.004} & $\mathrm{~N} / \mathrm{A}^{\mathrm{d}}$ \\
\hline \multicolumn{2}{|c|}{ Number and vignette characteristics } & .02 & & N/A \\
\hline \multicolumn{5}{|l|}{ No patient participation ${ }^{\mathrm{e}}$} \\
\hline 1 & 1 (reference) & N/A & 1 (reference) & N/A \\
\hline 2 & $1.10(0.97-1.25)$ & .13 & $1.10(0.97-1.25)$ & .15 \\
\hline \multicolumn{5}{|c|}{ Various means of informing patient and patient participation in decision making $f$} \\
\hline 3 & $1.07(0.94-1.21)$ & .32 & $1.06(0.93-1.21)$ & .36 \\
\hline 4 & $1.03(0.91-1.17)$ & .62 & $1.04(0.91-1.19)$ & .55 \\
\hline 5 & $1.02(0.90-1.16)$ & .77 & $1.01(0.89-1.15)$ & .85 \\
\hline 6 & $1.00(0.88-1.13)$ & .97 & $0.99(0.87-1.13)$ & .87 \\
\hline 7 & $0.97(0.85-1.11)$ & .66 & $0.96(0.84-1.10)$ & .56 \\
\hline 8 & $0.99(0.87-1.12)$ & .85 & $0.99(0.87-1.12)$ & .84 \\
\hline \multicolumn{5}{|c|}{ Patient involvement through shared decision making and use of a decision aid ${ }^{g}$} \\
\hline 9 & $1.03(0.90-1.17)$ & .70 & $1.02(0.90-1.16)$ & .75 \\
\hline 10 & $0.85(0.75-0.97)$ & .02 & $0.85(0.74-0.96)$ & .01 \\
\hline \multicolumn{2}{|l|}{ Alternative and course } & .006 & & N/A \\
\hline A: No cancer detected & 1 (reference) & N/A & 1 (reference) & N/A \\
\hline B: Treatable $\mathrm{PCa}^{\mathrm{h}}$ & $1.01(0.94-1.08)$ & .79 & $1.01(0.94-1.09)$ & .72 \\
\hline C: Fatal PCa & $0.91(0.85-0.98)$ & .008 & $0.91(0.84-0.97)$ & .007 \\
\hline
\end{tabular}

${ }^{\mathrm{a}}$ Comparison B compares responders to nonresponders among all individuals with the digital mailbox.

${ }^{\mathrm{b}}$ Odds ratios (ORs) denote the probability of response (ie, OR >1 means more likely to respond).

${ }^{\mathrm{c}}$ Adjusted for age and geography and mutually adjusted.

${ }^{\mathrm{d}} \mathrm{N} / \mathrm{A}$ : not applicable.

${ }^{\mathrm{e}}$ For example, in one version of the vignette, the fictional doctor performs the prostate-specific antigen (PSA) test without any test information and the patient described in the vignette is later successfully treated for prostate cancer (PCa) (alternative B).

${ }^{\mathrm{f}}$ For example, in one version, the patient chooses to have a PSA test following brief information about the test (showing no PCa; alternative A), and in other versions, the patient chooses not to have a test after being slightly nudged in favor or in disfavor of the PSA test and is later diagnosed with nontreatable PCa (alternative $\mathrm{C}$ ).

${ }^{\mathrm{g}}$ For example, in one version, the patient is subject to a shared decision-making aid and dialogue with the doctor, chooses not to take the PSA test, and is later diagnosed with treatable PCa (alternative B).

${ }^{\mathrm{h}} \mathrm{PCa}$ : prostate cancer. 
Table 5. Comparison of responders with the entire Danish population of men.

\begin{tabular}{|c|c|c|c|c|}
\hline Characteristic & Sample (all responders) $(\mathrm{N}=6756), \mathrm{n}(\%)$ & Denmark $(\mathrm{N}=951,247)^{\mathrm{a}}, \mathrm{n}(\%)$ & $P$ value & $P$ value adjusted ${ }^{\mathrm{b}}$ \\
\hline Age (years) & & & $<.001$ & $<.001$ \\
\hline $45-49$ & $935(13.84 \%)$ & $195,838(20.59 \%)$ & & \\
\hline $50-54$ & $1225(18.13 \%)$ & $212,293(22.32 \%)$ & & \\
\hline $55-59$ & $1368(20.25 \%)$ & $188,671(19.83 \%)$ & & \\
\hline $60-64$ & $1,406(20.81 \%)$ & $169,672(17.84 \%)$ & & \\
\hline $65-70$ & $1822(26.97 \%)$ & $187,926(19.76 \%)$ & & \\
\hline Municipality type & & & $<.001$ & .006 \\
\hline Urban municipality & $2828(41.86 \%)$ & $425,073(44.69 \%)$ & & \\
\hline Rural municipality & $2042(30.22 \%)$ & $279,102(29.34 \%)$ & & \\
\hline Urban-rural municipality & $1183(17.51 \%)$ & $159,240(16.74 \%)$ & & \\
\hline Outskirts municipality & $703(10.41 \%)$ & $90,985(9.57 \%)$ & & \\
\hline
\end{tabular}

${ }^{\mathrm{a}}$ Danish men aged 45 to 70 years as of January 1, 2019.

${ }^{\mathrm{b}}$ Adjusted for age and municipality type.

Tables 6 and 7 compare municipality-level characteristics in responders and nonresponders. In unadjusted models, higher population density, higher tax base, higher proportion of educated citizens, and higher proportion of citizens from non-Western countries were associated with lower RRs. Mutual adjustments were made; however, the associations weakened. Most consistently, RRs were found to be lower in population dense and higher tax base areas. Counts and frequencies corresponding to the data in Tables 6 and 7 are presented in Multimedia Appendix 3.

Table 6. Comparison of municipality-level characteristics in responders and nonresponders.

\begin{tabular}{|c|c|c|c|c|}
\hline Characteristic & $\begin{array}{l}\text { Comparison } \mathrm{A}^{\mathrm{a}} \\
(\mathrm{N}=23,839), \mathrm{OR}^{\mathrm{b}}(95 \% \\
\mathrm{CI})\end{array}$ & $\begin{array}{l}\text { Comparison A, } P \text { val- } \\
\text { ue }\end{array}$ & $\begin{array}{l}\text { Comparison } \mathrm{B}^{\mathrm{c}} \\
(\mathrm{N}=22,288), \text { OR }(95 \% \\
\mathrm{CI})\end{array}$ & $\begin{array}{l}\text { Comparison } \mathrm{B}, P \\
\text { value }\end{array}$ \\
\hline \multicolumn{5}{|l|}{ Population density (citizens/ $/ \mathbf{k m}^{2}$ ) } \\
\hline First tertile (least population density) & 1 (reference) & $\mathrm{N} / \mathrm{A}^{\mathrm{d}}$ & 1 (reference) & N/A \\
\hline Second tertile (middle population density) & $1.01(0.95-1.08)$ & .75 & $1.01(0.94-1.08)$ & .81 \\
\hline Third tertile (most population density) & $0.84(0.79-0.90)$ & $<.001$ & $0.85(0.79-0.91)$ & $<.001$ \\
\hline \multicolumn{5}{|l|}{ Tax per citizen } \\
\hline First tertile (lowest tax base) & 1 (reference) & N/A & 1 (reference) & N/A \\
\hline Second tertile (middle tax base) & $1.00(0.94-1.07)$ & .94 & $0.97(0.93-1.07)$ & .91 \\
\hline Third tertile (highest tax base) & $0.86(0.80-0.92)$ & $<.001$ & $0.85(0.79-0.91)$ & $<.001$ \\
\hline \multicolumn{5}{|c|}{ Proportion of citizens aged 25-64 years with higher education } \\
\hline First tertile (fewest with high education) & 1 (reference) & N/A & 1 (reference) & N/A \\
\hline $\begin{array}{l}\text { Second tertile (middle proportion with high edu- } \\
\text { cation) }\end{array}$ & $1.02(0.96-1.09)$ & .52 & $1.02(0.95-1.09)$ & .64 \\
\hline Third tertile (most with high education) & $0.89(0.83-0.95)$ & .001 & $0.89(0.83-0.95)$ & .001 \\
\hline \multicolumn{5}{|c|}{ Number of citizens from non-Western countries per 10,000 people } \\
\hline First tertile (fewest non-Western) & 1 (reference) & N/A & 1 (reference) & N/A \\
\hline Second tertile (middle number non-Western) & $1.05(0.98-1.12)$ & .15 & $1.07(1.00-1.15)$ & .048 \\
\hline Third tertile (most non-Western) & $0.89(0.83-0.95)$ & .001 & $0.91(0.84-0.97)$ & .007 \\
\hline
\end{tabular}

${ }^{\mathrm{a}}$ Comparison A compares responders to all nonresponders with or without the digital mailbox.

${ }^{\mathrm{b}} \mathrm{OR}$ : odds ratio.

${ }^{\mathrm{c}}$ Comparison B compares responders to nonresponders with the digital mailbox.

${ }^{\mathrm{d}} \mathrm{N} / \mathrm{A}$ : not applicable. 
Table 7. Comparison of municipality-level characteristics adjusted for population density, tax per citizen, proportion with higher education, and number of citizens from non-Western countries.

\begin{tabular}{|c|c|c|c|c|}
\hline Characteristic & $\begin{array}{l}\text { Comparison } \mathrm{A}^{\mathrm{a}} \\
(\mathrm{N}=23,839), \mathrm{OR}^{\mathrm{b}}(95 \% \\
\mathrm{CI})\end{array}$ & $\begin{array}{l}\text { Comparison A, } P \text { val- } \\
\text { ue }\end{array}$ & $\begin{array}{l}\text { Comparison } \mathrm{B}^{\mathrm{c}} \\
(\mathrm{N}=22,288), \text { OR }(95 \% \\
\mathrm{CI})\end{array}$ & $\begin{array}{l}\text { Comparison } \mathrm{B}, P \\
\text { value }\end{array}$ \\
\hline
\end{tabular}

Population density (citizens $/ \mathrm{km}^{2}$ )

First tertile (least population density)

1 (reference)

$\mathrm{N} / \mathrm{A}^{\mathrm{d}}$

1 (reference)

N/A

Second tertile (middle population density)

$0.98(0.90-1.08)$

.71

$0.98(0.89-1.07)$

.62

Third tertile (most population density)

$0.85(0.73-1.00)$

.049

$0.84(0.71-0.99)$

.03

Tax per citizen

$\begin{array}{lllll}\text { First tertile (lowest tax base) } & 1 \text { (reference) } & \text { N/A } & 1 \text { (reference) } & \text { N/A } \\ \text { Second tertile (middle tax base) } & 0.98(0.91-1.06) & .58 & 0.97(0.90-1.05) & .45 \\ \text { Third tertile (highest tax base) } & 0.91(0.83-1.00) & .054 & 0.89(0.81-0.98) & .02\end{array}$

Proportion of citizens aged 25-64 years with higher education

$\begin{array}{llccc}\text { First tertile (fewest with high education) } & 1 \text { (reference) } & \text { N/A } & 1 \text { (reference) } & \text { N/A } \\ \begin{array}{l}\text { Second tertile (middle proportion with high edu- } \\ \text { cation) }\end{array} & 1.07(0.98-1.18) & .14 & 1.07(0.98-1.18) & .15 \\ \text { Third tertile (most with high education) } & 1.03(0.92-1.16) & .59 & 1.03(0.92-1.16) & .57\end{array}$

Number of citizens from non-Western countries per 10,000 people

$\begin{array}{llccc}\text { First tertile (fewest non-Western) } & 1 \text { (reference) } & \text { N/A } & 1 \text { (reference) } & \text { N/A } \\ \text { Second tertile (middle number non-Western) } & 1.05(0.98-1.13) & .18 & 1.08(1.00-1.16) & .052 \\ \text { Third tertile (most non-Western) } & 1.04(0.92-1.19) & .50 & 1.08(0.95-1.23) & .22\end{array}$

${ }^{\mathrm{a} C}$ Comparison A compares responders to all nonresponders with or without the digital mailbox.

${ }^{\mathrm{b}} \mathrm{OR}$ : odds ratio.

${ }^{\mathrm{c}}$ Comparison $\mathrm{B}$ compares responders to nonresponders with the digital mailbox.

${ }^{\mathrm{d}} \mathrm{N} / \mathrm{A}$ : not applicable.

\section{Discussion}

\section{Principal Findings}

Using web-based surveys to collect data for public health research provides an opportunity to get easy access to potential responders while reducing efforts and research costs [7]. As is the case with other types of surveys, however, responders sometimes may not accurately represent the group of interest. In this study, we report on the representativeness of a large sample of adult men recruited through the use of a national web-based communication channel (the Danish digital mailbox). Our findings do not indicate that we received responses from only a highly selected group of the population. Nevertheless, we found that older men and men living in rural areas were more likely to respond than younger men, while RRs were lower in high economic resource areas. We discuss the findings in detail with reference to the existing literature below.

\section{Comments Regarding the Use of Digital Mailbox Solutions for Research}

There are multiple benefits of using web surveys for health research [9,23]. For example, participants may enter their responses confidentially and directly into the electronic database, allowing for more complete responses to sensitive questions and making subsequent data management much easier [23,24]. Furthermore, web surveys benefit from the ability to automatically branch into different scenarios, skipping irrelevant questions, etc [24]. As a result, savings are potentially larger compared with traditional mail or telephone surveys [25]. Uneven distribution in the use of information technologies among groups with different backgrounds may, however, challenge the use of web-based surveys for research [7]. In this regard, distributing surveys through a public platform, which is essentially mandatory for citizens to use, may be an attractive solution. Danish public authorities like hospitals and municipalities use the digital mailbox to inform citizens about tax issues, medical examinations, etc, adding to its legitimacy as an important platform for information exchange $[9,26]$. This may itself promote survey participation and, in part, prevent nonresponse, if not misused. It is noteworthy that $93.49 \%$ $(22,288 / 23,839)$ of our target population was registered with the digital mailbox, a finding that corresponds very well with available public reports on digital mailbox coverage (92.9\% among all Danish men as of the first quarter of 2019 [27]). As discussed below, this relatively high coverage is not necessarily reflected in a high RR.

The digital mailbox has been previously used for national-level survey research. Researchers recently reported on their 
experiences with using the digital mailbox for distribution of "The Danish Health and Morbidity Surveys" to describe the status and trends in health and morbidity in the adult Danish population aged 16 years or older [9]. The authors found that in $2017,90.1 \%$ of their sample was registered to use the digital mailbox; however, there were variations across age groups from $98.7 \%$ among individuals aged 24 years to $68.7 \%$ among individuals aged 65 years. Among men aged 45 years, they found RRs between $57.1 \%$ and $66.3 \%$. Their survey may generally appeal to a broader audience thereby contributing to a higher RR. The web-based survey methodology constitutes a particularly attractive opportunity for sending reminders with very little effort, and "The Danish Health and Morbidity Surveys" indeed benefitted from this ability by using a total of four reminders plus the introduction letter to increase the RR. Using multiple reminders, however, could potentially raise ethical concerns with regard to respecting citizens' rights not to join a research project.

\section{Discussion Regarding the Response Rate and Representativeness}

In "Encyclopedia of Survey Research Methods," Davern concluded that the standards for true representativeness in surveys are rarely met; however, "the biases produced by failures often are not severe enough to threaten the ultimate value of the survey findings" [8]. Likewise, there is no clear answer to the question about when an RR is acceptable [25]. Based on a review of 30 published studies, the RR itself was concluded to not be a good indicator of the magnitude of nonresponse bias [25,28]. Although very high RRs tended to reduce the chance of nonresponse bias, when bias did occur, the degree of bias was not necessarily low [28]. Furthermore, considerable variation often appeared in the degree of bias among variables within a study.

The RR generally can be affected by many factors [29,30]. For example, a smaller proportion of individuals responding probably would be expected in a more time-consuming survey. Previous research on the relationship between survey length and the RR has predominantly focused on other survey modalities (postal service and phone interviews) [31]. Our findings suggest that the relationship between the amount of survey material and the RR may not be that clear for web-based surveys. In any case, our RR (30\%) was lower than that usually seen in Danish population-based surveys [32,33]. In addition to the impact of only sending one reminder, the smaller RR may mirror the fact that the questionnaire was not available as a hard copy. Additionally, it may reflect that the RR is sometimes lower among men than among women $[7,33]$. Furthermore, it should be kept in mind that there was no direct benefit for survey responders apart from the sense of contributing to scientific knowledge about a patient's wish for involvement in health care decisions. Finally, to solve the problem with missing values, we constructed the web survey in such a way that participation without fully completing the questionnaire was not possible. This may have contributed to the smaller RR.

Our finding that RRs are higher in older men conflicts with the finding in a previous Danish survey [9] but seems to agree with the finding in another Danish investigation [33]. Keeping in mind that PCa risk rises with age, it is understandable that older men will be more concerned about this issue [12]. The higher RR may, however, also reflect that even if younger citizens have better access to the internet, older and retired people have more time available for research participation [7]. In accordance with previous findings, the RR seemed smaller in high income populations [33]. Associations overall were rather similar between comparisons of responders to all nonresponders and comparisons of responders to nonresponders with the digital mailbox, suggesting that nonresponders without the digital mailbox were fairly similar to nonresponders with the digital mailbox in terms of the variables under study.

\section{Interpretation of the Study Findings}

Our findings make it necessary to consider the possible consequences for further analyses of our survey data and the question of whether the composition of our sample tends to overrepresent particular viewpoints on health care decision-making. Regarding the association between age and preferences for patient involvement, some previous studies pointed toward older people having preferences for less participation in decision-making [34-37]. On the other hand, in the review by Hubbard et al that included 11 studies on the association between age and role preferences in decisions about cancer treatment, no general conclusion could be drawn [38]. Five studies reported that younger people were more likely to prefer a collaborative or active role in decision-making, but regarding $\mathrm{PCa}$ in particular, no relevant association with responder age was found in any one of three studies.

We found the RR to be much higher in rural municipalities. Furthermore, the RR was lower in areas with a higher tax base. Although the RR initially seemed to be lower in higher education areas, this association faded in adjusted analyses. Additionally, the RR seemed to be lower in areas with a higher proportion of citizens from non-Western countries, which might partly reflect the fact that the questionnaire was only available in Danish, although this association also disappeared in adjusted analyses controlling for the association with municipality-level population density and average tax per citizen.

A Cochrane review on patient decision aids suggested that the desire for involvement in health care decision-making, rather than being a stable trait, should be considered an adaptable way of thinking ("state") [39]. People simply have to be informed about why they should participate in a certain decision and understand the importance of their own preferences for outcomes of options (which outcomes matter most to them) before they are asked about their desire to participate. In spite of this, some studies have investigated associations between sociodemographic factors and preferences for involvement in decisions. Degner and Sloan found a nonrelevant trend for individuals from more rural areas to give away control to their physicians to a greater extent [36]. With regard to the impact of education, in the study by Rovner et al, college-educated men tended to want to make their own decisions about health care in benign prostatic hyperplasia, whereas noncollege-educated men tended to desire a shared approach [40]. Additionally, those preferring that decisions should be made mainly by the patient had a higher income. 
Correspondingly, in a large survey, Levinson et al found that more educated and healthier people were more likely to prefer an active role in decision-making [41]. On the other hand, African-American and Hispanic responders were more likely to prefer a passive role in decision-making. Generally, preferences for involvement increased with age up to 45 years and then declined. In a later study, Peek et al confirmed no racial differences in preferences for participation in decision-making [42].

While previous studies suggest that preferences for participation in health care decision-making may vary with the aforementioned factors, the latter factors may play no clear-cut role when it comes to decisions about cancer treatment. Hence, it was generally concluded from the review by Hubbard et al of 31 papers in total investigating patient preferences for participation in decision-making that the evidence on associations with age as well as gender, education level, marital status, socioeconomic status, and health status was inconclusive [38]. However, sample sizes were small in the majority of the studies. Patient preferences for involvement in decision-making are hypothesized to vary with age, socioeconomic status, etc [37], and therefore, statistical weighting may be warranted to control for skewness.

\section{Limitations}

Some previous studies have suggested gender differences regarding preferences for participation in decision-making [34-36,41,43]. This hardly can be controlled for in a survey including only male responders, but points to possible limitations regarding the generalizability of survey RR findings to women. In this regard, however, the role of gender has been questioned, at least when it comes to cancer issues [38]. Furthermore, it should be noted that only municipality-level register data on responders' sociodemographic characteristics were used. For example, the income of individual responders was not available. Likewise, more complex issues with regard to, for example, psychological disposition was not taken into consideration. In this regard, preferences for involvement in decision-making actually have been hypothesized to vary among personality types, while individuals' likelihood of survey participation simultaneously may vary with personality style [44-46].

\section{Conclusion}

The generalizability of survey findings to target populations is an important goal in research using web survey methodology. We wanted to establish the representativeness of responders in a large national survey investigating the desire of men to participate in decision-making about undergoing a PSA test, using the national digital mailbox platform. Our comparisons of responders to nonresponders point toward a reasonable representativeness of the sample. With regard to the result that responders did not fully represent men aged 45 to 70 years, previous research findings suggest that the variation found in our sample may not necessarily deteriorate forthcoming analyses on preferences for involvement in decision-making. In any case, identification of imbalances allows for statistical corrections to be made during the analysis of survey responses.

\section{Acknowledgments}

We would like to thank the survey responders for their participation and contributions to the study. The project was funded by grants of $€ 40,000$ from the Danish Health Insurance Foundation and $€ 5700$ from the Lilly \& Herbert Hansen's Foundation. The funding bodies had no influence on the design of the study. Moreover, the funding bodies had no influence on collection, analysis, and interpretation of data or writing of the manuscript.

\section{Authors' Contributions}

SB collected, analyzed, and interpreted the data used in this study and was a major contributor in writing the manuscript. AH assisted in collecting the data. SM assisted in analyzing the data. All authors assisted in interpreting the data. All authors read, commented on, and approved the final manuscript.

\section{Conflicts of Interest}

None declared.

\section{Multimedia Appendix 1}

Respondent numbers and response rates regarding the different questionnaire scenario variants of the survey. [DOCX File, 26 KB-Multimedia Appendix 1]

\section{Multimedia Appendix 2}

Time spent answering the questionnaire. [DOCX File , 26 KB-Multimedia Appendix 2]

\section{Multimedia Appendix 3}

Counts and proportions for comparisons of municipality-level characteristics in respondents and nonrespondents. [DOCX File, 25 KB-Multimedia Appendix 3] 


\section{References}

1. Bismark M, Dauer E, Paterson R, Studdert D. Accountability sought by patients following adverse events from medical care: the New Zealand experience. CMAJ 2006 Oct 10;175(8):889-894 [FREE Full text] [doi: 10.1503/cmaj.060429] [Medline: 17030939]

2. Beckman HB, Markakis KM, Suchman AL, Frankel RM. The doctor-patient relationship and malpractice. Lessons from plaintiff depositions. Arch Intern Med 1994 Jun 27;154(12):1365-1370. [Medline: 8002688]

3. Birkeland S, Depont Christensen R, Damsbo N, Kragstrup J. Characteristics of complaints resulting in disciplinary actions against Danish GPs. Scand J Prim Health Care 2013 Sep;31(3):153-157 [FREE Full text] [doi: 10.3109/02813432.2013.823768] [Medline: 23906082]

4. Huntington B, Kuhn N. Communication gaffes: a root cause of malpractice claims. Proc (Bayl Univ Med Cent) 2003 Apr;16(2):157-61; discussion 161 [FREE Full text] [doi: 10.1080/08998280.2003.11927898] [Medline: 16278732]

5. King JS, Moulton BW. Rethinking informed consent: the case for shared medical decision-making. Am J Law Med 2006;32(4):429-501. [doi: 10.1177/009885880603200401] [Medline: 17240730]

6. Birkeland S. Informed Consent Obtainment, Malpractice Litigation, and the Potential Role of Shared Decision-making Approaches. Eur. J. Health Law 2017 May 31;24(3):264-284 [FREE Full text] [doi: 10.1163/15718093-12341410]

7. Rhodes SD, Bowie DA, Hergenrather KC. Collecting behavioural data using the world wide web: considerations for researchers. J Epidemiol Community Health 2003 Jan;57(1):68-73 [FREE Full text] [doi: 10.1136/jech.57.1.68] [Medline: 12490652]

8. Davern M. Representative Sample. In: Lavrakas P, editor. Encyclopedia of Survey Research Methods. Thousand Oaks, California: SAGE Publications, Inc; 2008.

9. Jensen HA, Ekholm O, Davidsen M, Christensen AI. The Danish health and morbidity surveys: study design and participant characteristics. BMC Med Res Methodol 2019 May 03;19(1):91 [FREE Full text] [doi: 10.1186/s12874-019-0733-9] [Medline: $\underline{\text { 31053088] }}$

10. REDCap. URL: https://www.project-redcap.org/ [accessed 2020-08-11]

11. Birkeland S, Pedersen SS, Haakonsson AK, Barry MJ, Rottmann N. Men's view on participation in decisions about prostate-specific antigen (PSA) screening: patient and public involvement in development of a survey. BMC Med Inform Decis Mak 2020 Apr 06;20(1):65 [FREE Full text] [doi: 10.1186/s12911-020-1077-4] [Medline: $\underline{\text { 32252729] }}$

12. US Preventive Services Task Force, Grossman DC, Curry SJ, Owens DK, Bibbins-Domingo K, Caughey AB, et al. Screening for Prostate Cancer: US Preventive Services Task Force Recommendation Statement. JAMA 2018 May 08;319(18):1901-1913. [doi: 10.1001/jama.2018.3710] [Medline: 29801017]

13. Mottet N, Bellmunt J, Bolla M, Briers E, Cumberbatch MG, De Santis M, et al. EAU-ESTRO-SIOG Guidelines on Prostate Cancer. Part 1: Screening, Diagnosis, and Local Treatment with Curative Intent. Eur Urol 2017 Apr;71(4):618-629. [doi: 10.1016/j.eururo.2016.08.003] [Medline: 27568654]

14. Social- og Indenrigsministeriet. URL: http://www.noegletal.dk/ [accessed 2020-07-30]

15. Olsen KR, Sørensen TH, Gyrd-Hansen D. [Association between productivity, list size, patient and practice characteristics in general practice]. Ugeskr Laeger 2010 Apr 19;172(16):1192-1196. [Medline: 20423660]

16. Birkeland S, Christensen RD, Damsbo N, Kragstrup J. Patient complaint cases in primary health care: what are the characteristics of general practitioners involved? Biomed Res Int 2013;2013:807204 [FREE Full text] [doi: 10.1155/2013/807204] [Medline: 24027764]

17. Vandenbroucke JP, von Elm E, Altman DG, Gøtzsche PC, Mulrow CD, Pocock SJ, STROBE Initiative. Strengthening the Reporting of Observational Studies in Epidemiology (STROBE): explanation and elaboration. PLoS Med 2007 Oct 16;4(10):e297 [FREE Full text] [doi: 10.1371/journal.pmed.0040297] [Medline: 17941715]

18. DeWitt T, Brady MK. Rethinking Service Recovery Strategies. Journal of Service Research 2016 Jun 29;6(2):193-207. [doi: $10.1177 / 1094670503257048]$

19. Altman D. Practical Statistics for Medical Research. London: Chapman and Hall; 1991.

20. Barry MJ, Wexler RM, Brackett CD, Sepucha KR, Simmons LH, Gerstein BS, et al. Responses to a Decision Aid on Prostate Cancer Screening in Primary Care Practices. Am J Prev Med 2015 Oct;49(4):520-525. [doi: 10.1016/j.amepre.2015.03.002] [Medline: 25960395]

21. Kristensen I, Kjeldsen C, Dalgaard T. Landdistriktskommuner - indikatorer for landdistrikt. PURE.au.dk. Tjele: Danmarks Jordbrugsforskning; 2007 Feb 28. URL: https://pure.au.dk/ws/files/4594133/RapLanddistrikt2007 20070201.pdf [accessed 2020-08-11]

22. Danmarks Statistik. URL: https://www.dst.dk/da [accessed 2020-07-30]

23. Couper M. Web surveys: a review of issues and approaches. Public Opin Q 2000;64(4):464-494. [Medline: 11171027]

24. Ryan JM, Corry JR, Attewell R, Smithson MJ. A comparison of an electronic version of the SF-36 General Health Questionnaire to the standard paper version. Qual Life Res 2002 Feb;11(1):19-26. [doi: 10.1023/a:1014415709997] [Medline: 12003052] 
25. Sinclair M, O'Toole J, Malawaraarachchi M, Leder K. Comparison of response rates and cost-effectiveness for a community-based survey: postal, internet and telephone modes with generic or personalised recruitment approaches. BMC Med Res Methodol 2012 Aug 31;12:132 [FREE Full text] [doi: 10.1186/1471-2288-12-132] [Medline: 22938205]

26. Porter SR, Whitcomb ME. Mixed-Mode Contacts In Web Surveys: Paper is Not Necessarily Better. Public Opinion Quarterly 2007 Sep 18;71(4):635-648. [doi: 10.1093/poq/nfm038]

27. Digitaliseringsstyrelsen. URL: https://digst.dk/it-loesninger/digital-post/om-loesningen/tal-og-statistik-om-digital-post/ [accessed 2020-07-30]

28. Groves R. Nonresponse Rates and Nonresponse Bias in Household Surveys. The Public Opinion Quarterly 2006;70(5):646-675 [FREE Full text] [doi: 10.1093/poq/nfl033]

29. Marcus B, Bosnjak M, Lindner S, Pilischenko S, Schütz A. Compensating for Low Topic Interest and Long Surveys. Social Science Computer Review 2016 Aug 18;25(3):372-383 [FREE Full text] [doi: 10.1177/0894439307297606]

30. Turk T, Elhady MT, Rashed S, Abdelkhalek M, Nasef SA, Khallaf AM, et al. Quality of reporting web-based and non-web-based survey studies: What authors, reviewers and consumers should consider. PLoS One 2018;13(6):e0194239 [FREE Full text] [doi: 10.1371/journal.pone.0194239] [Medline: 29912881]

31. Burkhart Q, Orr N, Brown JA, Hays RD, Cleary PD, Beckett MK, et al. Associations of Mail Survey Length and Layout With Response Rates. Med Care Res Rev 2019 Nov 20:1077558719888407. [doi: 10.1177/1077558719888407] [Medline: 31747849]

32. Rasmussen S, Søndergaard J, Larsen PV, Balasubramaniam K, Elnegaard S, Svendsen RP, et al. The Danish Symptom Cohort: Questionnaire and Feasibility in the Nationwide Study on Symptom Experience and Healthcare-Seeking among 100000 Individuals. Int J Family Med 2014;2014:187280 [FREE Full text] [doi: 10.1155/2014/187280] [Medline: 25147736]

33. Elnegaard S, Andersen RS, Pedersen AF, Larsen PV, Søndergaard J, Rasmussen S, et al. Self-reported symptoms and healthcare seeking in the general population--exploring "The Symptom Iceberg". BMC Public Health 2015 Jul 21;15:685 [FREE Full text] [doi: 10.1186/s12889-015-2034-5] [Medline: 26195232]

34. Marahrens L, Kern R, Ziemssen T, Fritsche A, Martus P, Ziemssen F, et al. Patients' preferences for involvement in the decision-making process for treating diabetic retinopathy. BMC Ophthalmol 2017 Aug 09;17(1):139 [FREE Full text] [doi: 10.1186/s12886-017-0526-z] [Medline: 28793881]

35. Stiggelbout AM, Kiebert GM. A role for the sick role. Patient preferences regarding information and participation in clinical decision-making. CMAJ 1997 Aug 15;157(4):383-389 [FREE Full text] [Medline: 9275945]

36. Degner LF, Sloan JA. Decision making during serious illness: what role do patients really want to play? J Clin Epidemiol 1992 Sep;45(9):941-950. [doi: 10.1016/0895-4356(92)90110-9] [Medline: 1432023]

37. Robinson A, Thomson R. Variability in patient preferences for participating in medical decision making: implication for the use of decision support tools. Qual Health Care 2001 Sep;10 Suppl 1:i34-i38 [FREE Full text] [doi: 10.1136/qhc.0100034] [Medline: 11533436$]$

38. Hubbard G, Kidd L, Donaghy E. Preferences for involvement in treatment decision making of patients with cancer: a review of the literature. Eur J Oncol Nurs 2008 Sep;12(4):299-318. [doi: 10.1016/j.ejon.2008.03.004] [Medline: 18486552]

39. Stacey D, Légaré F, Lewis K, Barry MJ, Bennett CL, Eden KB, et al. Decision aids for people facing health treatment or screening decisions. Cochrane Database Syst Rev 2017 Apr 12;4:CD001431 [FREE Full text] [doi: 10.1002/14651858.CD001431.pub5] [Medline: 28402085]

40. Rovner DR, Wills CE, Bonham V, Williams G, Lillie J, Kelly-Blake K, et al. Decision aids for benign prostatic hyperplasia: applicability across race and education. Med Decis Making 2004;24(4):359-366. [doi: 10.1177/0272989X04267010] [Medline: 15271274$]$

41. Levinson W, Kao A, Kuby A, Thisted RA. Not all patients want to participate in decision making. A national study of public preferences. J Gen Intern Med 2005 Jun;20(6):531-535 [FREE Full text] [doi: 10.1111/j.1525-1497.2005.04101.x] [Medline: 15987329$]$

42. Peek ME, Tang H, Cargill A, Chin MH. Are there racial differences in patients' shared decision-making preferences and behaviors among patients with diabetes? Med Decis Making 2011;31(3):422-431 [FREE Full text] [doi: 10.1177/0272989X10384739] [Medline: 21127318]

43. Flynn KE, Smith MA, Vanness D. A typology of preferences for participation in healthcare decision making. Soc Sci Med 2006 Sep;63(5):1158-1169 [FREE Full text] [doi: 10.1016/j.socscimed.2006.03.030] [Medline: 16697096]

44. Reamer E, Yang F, Holmes-Rovner M, Liu J, Xu J. Influence of Men's Personality and Social Support on Treatment Decision-Making for Localized Prostate Cancer. Biomed Res Int 2017;2017:1467056 [FREE Full text] [doi: 10.1155/2017/1467056] [Medline: 28785574]

45. Orom H, Penner LA, West BT, Downs TM, Rayford W, Underwood W. Personality predicts prostate cancer treatment decision-making difficulty and satisfaction. Psychooncology 2009 Mar;18(3):290-299 [FREE Full text] [doi: 10.1002/pon.1385] [Medline: 18821530]

46. Nestler S, Thielsch M, Vasilev E, Back M. Will They Stay or Will They Go? Personality Predictors of Dropout in an Online Study. International Journal of Internet Science 2015:37-48. 


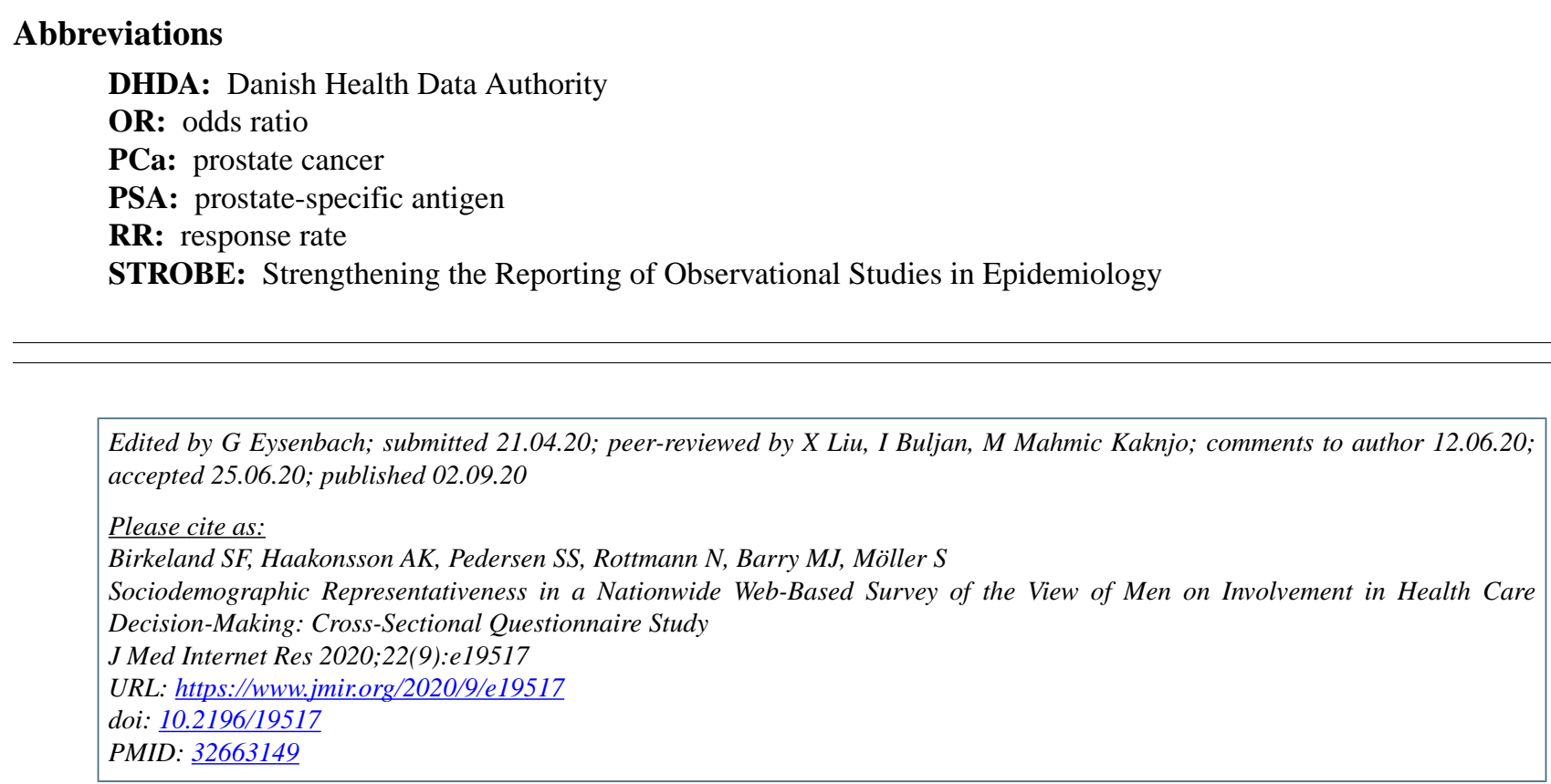

CS $\varnothing$ ren F Birkeland, Anders K Haakonsson, Susanne S Pedersen, Nina Rottmann, Michael J Barry, Sören Möller. Originally published in the Journal of Medical Internet Research (http://www.jmir.org), 02.09.2020. This is an open-access article distributed under the terms of the Creative Commons Attribution License (https:/creativecommons.org/licenses/by/4.0/), which permits unrestricted use, distribution, and reproduction in any medium, provided the original work, first published in the Journal of Medical Internet Research, is properly cited. The complete bibliographic information, a link to the original publication on http://www.jmir.org/, as well as this copyright and license information must be included. 